Se consultaron además la Separata Presupuestal del Ministerio de Educación, informes de los maestros y otras fuentes secundarias.

El análisis de la información comprende la descripción y explicación de las observaciones realizadas sobre terreno, opiniones de los estamentos entrevistados y cruces de variables obtenidos mediante un programa de computadores.

Actualmente el estudio se encuentra en la corrección del informe final para su publicación.

\title{
EVALUACION DEL PROGRAMA DE JORNADAS ADICIONALES
}

\section{Planteamiento del problema}

En el mes de octubre de 1974, el Gobierno Nacional congelé las matrículas y pensiones de los planteles privados, quienes plantearon derogar esta disposición por ser "lesiva" a sus intereses. El Ministerio de Educación entró a buscar una solución al problema de común acuerdo con los colegios privados, y en noviembre del mismo año, firmaron un convenio en el cual los colegios privados se comprometieron a prestar las instalaciones locativas para el funcionamiento de cursos adicionales a los existentes y en jornada diferente, como contraprestación al aumento porcentual en las matrículas y pensiones.

Este mecanismo, a la vez que permitiría un aumento racional y controlado en las matrículas y pensiones, proporcionaría cupos a estudiantes de escasos recursos económicos.

El 26 de diciembre de 1974 el Ministerio de Educación Nacional dio a conocer el Decreto 2854, en el cual se ordenó el establecimiento de jornadas adicionales en todos los planteles oficiales y no oficiales del país.

A partir de esta fecha se dicté una serie de Decretos y Resoluciones que dieron forma al Programa de jornadas adicionales al establecer el marco legal para su funcionamiento.

\section{Objetivos}

La Evaluación del Programa de Jornadas Adicionales tuvo como propósito ofrecer un análisis de los resultados obtenidos en tres años de funcionamiento, que le permitiera al Ministerio de Educación Nacional tomar las medidas para su mejoramiento y para aumentar la cobertura del sistema educativo. De acuerdo con este propósito el objetivo de la evaluación se centré en el análisis de la administración, funcionamiento y cobertura del Programa durante el período 1975-1977.

Especialmente, el estudio consideró los siguientes aspectos:

1. Análisis de costos y financiación del programa.

2. Evaluación del funcionamiento de la Jornada a nivel Institucional. 
3. Situación laboral de los, profesores de la Jornada Adicional y comparación de la calidad de estos profesores con los de la Jornada Ordinaria.

4. Relación del número de alumnos beneficiados por año y nivel socio económico de los mismos en ambas jornadas.

5. Análisis del rendimiento interno del Programa: tasas de retención, deserción e indices de crecimiento.

6. Opiniones y actitudes de los rectores, profesores, delegados regionales, asociaciones de colegios privados y sindicatos, sobre el funcionamiento del Programa.

\section{Metodología}

Mediante el análisis de las normas legales que sigue el funcionamiento del Programa se ubicaron algunas de las variables a evaluar, para lo cual se elaboré un cuestionario dirigido a los rectores de los planteles. Además se obtuvo información secundaria a través de los delegados de los Fondos Educativos Regionales y documentos de archivo. El cuestionario se envió a los 443 planteles que ofrecían jornada adicional en 22 departamentos y el Distrito de Bogotá.

En una segunda etapa se realizaron entrevistas abiertas con los delegados de los FER, docentes, federaciones de colegios privados y la Asociación Colombiana de Profesores de Educación Secundaria, ACPES, dirigidas a conocer las opiniones de estos estamentos sobre la administración, funcionamiento y resultados del Programa.

\section{Resultados}

El análisis de la información conduce a la conclusión de que el programa no ha generado un aumento significativo de cupos para la población escolar —en 1977 representa un $2.8 \%$ del total de la matrícula de la educación media en el país- en tanto que se caracteriza por el continuo déficit presupuestal, la inconformidad de los profesores por tener exceso de carga académica, trabajar en áreas diferentes a las de su especialidad y en doble jornada —ordinaria y adicional- demora e incumplimiento en el pago de salarios, criterios no profesionales para el nombramiento de profesores, etc.

La incoherencia entre oferta y demanda por educación, plantea la necesidad de hacer una ocupación más racional de los planteles subutilizados, orientar una mayor parte del presupuesto y de los auxilios para la construcción y dotación de planteles, además de una mejor utilización de los recursos humanos existentes. En torno a estos aspectos, el estudio plantea que el Ministerio de Educación o las Secretarías de Educación asuman la administración del programa de Jornadas Adicionales y se convierta en programa regular adoptando uno o más, de acuerdo a las condiciones concretas de cada departamento, de los siguientes mecanismos:

1. Ocupar los planteles entregados por el ICCE, sub-utilizados en la actualidad.

2. Ampliar planteles nacionales.

3. Construir nuevos planteles.

4. Tomar en arriendo locales adecuados. 
5. Aprovechar locales sub-utilizados propiedad de los departamentos, municipios, distrito, comunidades religiosas, etc., efectuando contratos de comodato.

Otra alternativa es la continuación transitoria del programa modificando en algunos aspectos su funcionamiento, de acuerdo con los resultados de la evaluación.

Finalmente propone la conformación de un equipo que entre a estudiar y ejecutar las recomendaciones dadas en el estudio.

\section{EVALUACION DE LOS PLANTELES COOPERATIVOS}

\section{Planteamiento del problema}

Por definición, los planteles cooperativos son entidades educativas sin ánimo de lucro, en las cuales participan activamente los padres de familia y otras personas interesadas en obtener servicios educativos, bajo la forma legal de cooperativas especializadas de Educación con la orientación técnica y apoyo del Ministerio de Educación, Superintendencia Nacional de Cooperativas y algunas agencias gubernamentales y privadas.

El programa de Promoción y Fomento de Planteles Cooperativos se implantó en el país por medio de la Ley $9^{\mathrm{a}}$ de 1971 y su Decreto Reglamentario No. 2472 de 1972, como una dependencia del Ministerio de Educación Nacional.

Desde sus comienzos y luego en la medida en que se fue institucionalizando como programa con participación del Gobierno, los planteles cooperativos han ido sustentando la imagen de ser una metodología de integración de recursos para resolver una necesidad social, sentida por comunidades en donde el Estado no ha llevado los servicios educativos, o estos son insuficientes, y la educación privada por razones económicas desventajosas, tampoco los ha organizado.

Estos planteles tienen múltiples beneficios, entre otros, el de recibir profesores a cargo del Presupuesto Nacional. Sin embargo se desconocen los logros alcanzados por este tipo de educación, así como la participación de la comunidad en la Cooperativa, en relación con la ayuda económica proveniente del Estado.

\section{Objetivos}

Con el fin de presentar elementos de análisis y alternativas sobre la problemática inherente al funcionamiento de los Planteles Cooperativos, el estudio se propuso como objetivos:

1. Evaluar los insumos materiales, financieros y humanos del programa.

2. Determinar la calidad académica ofrecida, a nivel de los estudiantes.

3. Evaluar el funcionamiento administrativo del plantel y la cooperativa. 